\title{
DEVELOPING HIGHER EDUCATION INSTITUTIONS AS EFFECTIVE LEARNING COMMUNITIES: APPROACHES, PRACTICES AND POLICY LEVERS AT ONE PORTUGUESE UNIVERSITY
}

\author{
N. Jesus-Silva, P. Morais, J. Caramelo-Gomes, C. Costa-Lobo \\ Universidade Portucalense (PORTUGAL)
}

\begin{abstract}
In Europe, when speaking of quality assurance of Higher Education Institutions (HEI), the point of reference is the Standard and guidelines for quality assurance in the European Higher Education Area document, devised by the European Association for Quality Assurance in Higher Education. This document establishes a set of guidelines for the Internal Systems of Quality Assurance (ISQA) of the $\mathrm{HEI}$ and, also includes, guidelines for the creation of quality assurance agencies, such as the Portuguese Agency for Assessment and Accreditation of Higher Education (A3ES), Agency which establish standards, evaluate and ensure the quality of the $\mathrm{HEl}$ in the different member countries of the Higher Education European Space. In Portugal, the A3ES created a Manual for the ISQA audit process which specifies the objectives, the form of organization and operation of the institutional audit model adopted by the A3ES, so as to certificate the ISQA in the HEI. Besides the two stated references which are aimed, specifically, to the $\mathrm{HEI}$, when discussing management systems certification, it's also relevant to mention the ISO norms. The ISO 9001 is the most used norm of management systems worldwide, establishing itself as international reference for the Certification of Quality Assurance of Management Systems. The adoption of a Quality Assurance System is, according to this norm, a strategical decision of the organization. The strategy formulated to ensure quality in Higher Education uses internal systems of quality assurance, of the institutions responsibility, and also external systems, of the quality assurance agencies responsibility. The development of quality assurance systems demands a balance between the HEl's actions and the external procedures of quality assurance purposed by the agencies, in the case of Portugal, the A3ES. $\mathrm{HEls}$ are required to establish their own self-evaluation mechanisms. For this purpose, promoting a solid internal quality culture is elemental to strengthen effective strategies of institutional evaluation. Related to its continuous improvement process, Portucalense University, a private HEI, located in Portugal, decided to certificate its quality assurance system, both by the A3ES and by the ISO 9001 . This article describes the developed practices in this double certification process. The perception of the areas with greater need of being leveraged, the respective improvements to be applied, and the better way of proceeding in regard to the continuous improvement of the processes, either of management, value chain and support or services, stand out as results of this content analysis. With this study, it is intended to contribute with good practices for the attainment of the certifications and the continuous improvement of the $\mathrm{HEl}$ in question.
\end{abstract}

Keywords: European Standards and Guidelines; Quality in Higher Education; Assessment and Accreditation; Internal Systems of Quality Assurance; ISO 9001:2015.

\section{INTRODUCTION}

$\mathrm{HEl}$ 's across the globe are increasingly pressed to find ways of proving their worth. The complexity and uncertainty of society and the economy require HEls to continuously adapt while upholding quality standards. HEls must learn how to best serve the student community. At Europe, as elsewhere, there is an ongoing need to improve quality in higher education. Today, in addition to the two traditional missions of research and teaching, universities are expected to play a 'third mission', mission linked to economic development and involves knowledge transfer to society (Sousa, Magalhães, Castro Lopes, Fernandes, Costa-Lobo, 2017). The role of HEls in society and the economy has been evolving and assuming itself as a conducive to competition in the global economy (Sá, Dias, Sá, 2017).In recent years, the authors of social cognitive theory of career have been explaining the influence of academic experiences at $\mathrm{HEl}$ in various aspects of vocational development (Costa-Lobo, 2011; Costa-Lobo and Ferreira, 2012) emphasizing that academic experiences are a source of relevant information in the process of constructing meaning the role of modeling, evaluation, performance and merit, contributing to the development of higher education students vocational interests and values. Quality improvement models from business have not been widely embraced, and many other approaches to accountability 
seem to induce minimal compliance. This paper aims to contend that learning communities represent a viable alternative in the quest for quality. By restructuring the curriculum and promoting creative collaboration, learning communities have become a major reform effort in Europe colleges.

\subsection{Standards and Guidelines for Quality Assurance in the European Higher Education Area (ESG)}

A key goal of the Standards and Guidelines for Quality Assurance in the European Higher Education Area (ESG) is to contribute to the common understanding of quality assurance for learning and teaching across borders and among all stakeholders. They have played and will continue to play an important role in the development of national and institutional quality assurance systems across the European Higher Education Area (EHEA) and cross-border cooperation. Engagement with quality assurance processes, particularly the external ones, allows European higher education systems to demonstrate quality and increase transparency, thus helping to build mutual trust and better recognition of their qualifications, programmes and other provision. The ESG are used by institutions and quality assurance agencies as a reference document for internal and external quality assurance systems in higher education. Moreover, they are used by the European Quality Assurance Register (EQAR), which is responsible for the register of quality assurance agencies that comply with the ESG.

ESG: purposes and principles:

- They set a common framework for quality assurance systems for learning and teaching at European, national and institutional level;

- They enable the assurance and improvement of quality of higher education in the European higher education area;

- They support mutual trust, thus facilitating recognition and mobility within and across national borders;

- They provide information on quality assurance in the EHEA.

The ESG are based on the following four principles for quality assurance in the EHEA:

- Higher education institutions have primary responsibility for the quality of their provision and its assurance;

- Quality assurance responds to the diversity of higher education systems, institutions, programmes and students;

- Quality assurance supports the development of a quality culture;

- Quality assurance takes into account the needs and expectations of students, all other stakeholders and society.

The standards for quality assurance have been divided into three parts:

- Internal quality assurance: policy for quality assurance; design and approval of programmes; student-centred learning, teaching and assessment; student admission, progression, recognition and certification; teaching staff; learning resources and student support; information management; public information; on-going monitoring and periodic review of programmes; cyclical external quality assurance.

- External quality assurance: consideration of internal quality assurance; designing methodologies fit for purpose; implementing processes; peer-review experts; criteria for outcomes; reporting; complaints and appeals.

- Quality assurance agencies: activities, policy and processes for quality assurance; official status; independence; thematic analysis; resources; internal quality assurance and professional conduct; cyclical external review of agencies.

\subsection{Portuguese Agency for Assessment and Accreditation of Higher Education (A3ES)}

The references for the Internal Quality Assurance Systems (SIGQ) are underpinned by the following vectors: 
- quality assurance policy: adoption of quality assurance policy and pursuit of quality objectives: The institution has consolidated a culture of quality, backed by a policy and quality objectives that are formally defined and publicly available.

- the core processes of the institutional mission: - teaching and learning, research and development (university education) or oriented research and high-level professional development (polytechnic education), and interinstitutional and community collaboration including internationalization. Design and approval of the training offer: The institution has processes for the design and approval of its training offer, ensuring that the courses taught are designed and structured so that they can achieve the stated objectives, namely the learning objectives. The qualification and qualification achieved in each course, as well as the corresponding level in the national and European qualifications frameworks in higher education, are clearly specified and publicized. Student-centered teaching, learning and assessment: The institution adopts the most appropriate procedures to ensure that teaching is delivered in a way that favors an active role of the student in the creation of the learning process, as well as evaluation processes for students who are consonant with approach. Admission of students, progression, recognition and certification: The institution is endowed with duly approved and publicized regulations covering all phases of the student's study cycle in the institution (e.g., student admission, progression, recognition and certification), which consistently applied. Continuous monitoring and periodic review of courses: The institution promotes the monitoring and periodic review of its courses, in order to ensure that they achieve the objectives set for them and respond to the needs of students and society. The revisions made lead to the continuous improvement of the course and the actions planned or executed as a result of this process are communicated to all interested parties. Research and development / Targeted research and high-level professional development: The institution has mechanisms to promote, evaluate and improve high-level scientific, technological, artistic and professional development appropriate to its institutional mission. Inter-institutional and community collaboration: The institution has mechanisms to promote, evaluate and improve inter-institutional collaboration and with the community, in particular as regards its contribution to regional and national development. Internationalization: The institution has mechanisms to promote, evaluate and improve its international cooperation activities.

- The management of human resources and material resources and support services: Human resources: The institution has appropriate mechanisms, applied in a fair and transparent manner, to ensure that the recruitment, management and training of its teaching staff and nonteaching staff is carried out with the necessary guarantees of qualification and competence so that they can carry out effectively their functions. Material resources and services: The institution has mechanisms that allow it to plan, manage and improve services and material resources with a view to the adequate development of students' learning and other scientific educational activities.

- Information management and publicity: Information management: The institution has mechanisms to guarantee the collection, analysis and use of results and other information relevant to the effective management of courses and other activities. Public information: The institution has mechanisms that allow the publication of clear, precise, objective, updated, impartial and easily accessible information about the activities it carries out

- The periodic external evaluation: The cyclical character of the external quality assurance: The institution is subject to periodic external evaluation processes, in line with the European Standards and Guidelines for Higher Education (ESG).

The evaluation to be carried out by the External Evaluation Committee (CAE) will focus on these areas, in terms of an assessment of their degree of development against the objectives defined by the institution, taking into account the references to the internal quality assurance systems defined by Agency. The results of this assessment will be expressed in an objective manner, on a four-stage scale of development of each of the assessed items, namely: 1 - Insufficient development; 2 - Partial development; 3 - Substantial development; 4 - Very advanced development.

A favorable decision to certify an internal quality assurance system will cumulatively require the following conditions: a minimum "partial development" assessment in all specific areas of analysis; an appreciation of at least "substantial development" in relation to the teaching and learning items and the system as a whole; no more than four areas with "partial development" appreciation. In the case of areas considered as "partial development", a favorable decision may be conditional on compliance 
with the conditions and deadlines that are explicitly set forth in the Agency's decision. In the case of a "non-certification" decision, the institution may only request a new audit process after two years from the previous audit.

\subsection{Norma ISO 9001: 2015 - Quality management systems}

This Standard reflects a set of references where it is stated:

Context of organization - Understand the organization and its context, Understand customer needs and expectations, determine the scope of the Quality Assurance and Management System (SGGQ)

Leadership - Leadership and Commitment, Policy Roles, responsibilities and organizational authorities

Planning - Actions to address risks and opportunities, Management Objectives and planning to achieve them

Support- Resources, Skills, Awareness, Communication, Documented information

Operationalization - Operational planning and control

Performance evaluation - Monitoring, measurement, analysis and evaluation, Internal audit, Management Review

Improvement - Non-compliance and corrective action, Continuous improvement

This Standard brings us the concept of risk-based thinking, although this was already implicit in previous standards through preventive actions. Since risk is an effect of uncertainty, it can have positive or negative effects. A positive deviation from the planned outcome that results from a risk may provide an opportunity, but not all the positive effects of the risk result in opportunities. Opportunities may arise as a result of a favorable situation to achieve a desired outcome. The management system is a preventive tool, the concept of risk-based approach encompasses the concept of preventive action, the clause of ISO 9001: 2008 on preventive actions was consequently eliminated, the riskbased approach in ISO 9001: 2015: reduce need for prescriptive requirements and superseded by performance-based requirements, in this standard the concept is explicit but a formal approach to risk management is not required; organizations can develop a more extensive risk approach if they so wish or if required.

\section{METHODOLOGY}

This work was based on the option of the case study. In the field of social projects, the case study has become, in the last decades, a methodology for improving the work of non-governmental organizations and surveying new proposals for social intervention. It has become common in the 1990 s to carry out exemplary case studies, whether from the point of view of its political or social aspect.The option for the case study was a conscious choice, since it was intended to investigate a situation that can not be understood from quantitative methods. Documents were analysed, and field notes were taken. The decision whether or not to carry out a case study was much more epistemological than methodological. In this study objectives focus on humanistic outcomes rather than behavioral outcomes or individual differences, information was subject to scrutiny based on credibility, and the chosen unit (Portucalense University) in itself is a worthy case to be studied.

Portucalense University is a Portuguese institution, located in the north of the country, in the coastal zone, in the city of Porto. In October 1986 Portucalense University (UPT) began its academic activities, starting with an ambitious project: to build an institution where the search for and transmission of new knowledge, a goal so much of the vocation of a university, was associated with the deepening of the knowledge already made, to the tradition of a history and culture of many centuries, preparing young people for the challenges of modern times. At present, the UPT has approximately 200 collaborators, 143 teachers and 57 non-teaching staff. At present, the Institution has 4 Organic Units and 3 Research Centers, one of which is the Portucalense Institute for Legal Research (IJP) accredited by the Foundation for Science and Technology.

\section{RESULTS}

In order to systematically monitor its academic quality, the university created in January 2000 the Permanent Evaluation Office (GPA) subordinated to the Vice-Rector and appointed to oversee the 
evaluation process, and even before that date the University promoted the evaluation of its courses and teachers through surveys applied to students.

At the same time (2000-2005) the University participated in the second cycle of evaluation of nonpublic university institutions, promoted by the National Council for the Evaluation of Higher Education. In July 2002, the GPA was renamed Permanent Office for Evaluation and Quality, reflecting the new functions assigned to it by the Rectory.

In 2007, as part of the implementation of the "Bologna Process" and the changes planned for quality assessment in Higher Education, the GPAQ assumed the name of Quality and Evaluation Office (GQA), with the main objective of assessing the quality of services and of teaching at the University and contribute to the implementation of training measures in accordance with European standards for accreditation. This cabinet continues to operate to date. The University has unambiguously assumed the principle that quality and quality assurance are one of the fundamental vectors for its operation and development. This principle is enshrined in the commitment of the University to develop its project through a culture of quality based on the responsibility and effectiveness of its action for greater social cohesion.

In the context of these concerns, the University hired an external company, HayGroup, to develop an Integrated Human Resources Project (2010/2012), which led to the implementation of a new organizational model capable of responding to the challenges in terms of institution development, as well as implementation of a system of performance evaluation (SAD) of all employees (teachers and non-teachers), in force since the school year 2012/13, and applied annually. In that same year, the Regulation of Performance Evaluation of Teachers (RAD) was implemented, in which evaluation is made in four dimensions: teaching, research, participation in management and knowledge transfer. With a view to continuous improvement, the University has implemented an internal quality management system. In this context, the University decided, at first, to focus on Quality Certification through the implementation of NP EN ISO 9001: 2008 Quality Assurance and Management Systems, which refers to the requirements of a quality management and assurance system with Effectiveness of student satisfaction and other stakeholders through recognition by an external and independent entity. The system was certified in December 2014 and was revalidated in the following years. The new NP EN ISO 9001: 2015 was implemented in February 2018.

In order to guarantee the quality and continuous improvement in the structure and mechanisms for the study and research cycles and for all the support and management processes, the UPT institutionalized, since 2013, the practice of internal audits. The Quality Assurance and Management System includes, among others, the monitoring of processes as a way of continuously improving UPT's activities. These processes are monitored by means of quantitative and trend indicators, with reference to the benchmarks, according to the most recent A3ES Audit Manual, and the implementation since 2015 of measures that enrich the internal quality assurance system according to the European Standards and Guidelines 2015, from a perspective of continuous improvement. In 2015 the UPT submitted its SIGQ to the auditing process by the A3ES; Overall, the system was well evaluated, not having achieved the necessary score in the "System as a whole" point that would guarantee accreditation; However, it is important to participate in this process, which allowed to reinforce and produce some changes in support to the system, namely, Quality Management Manual and associated procedures. This process contributed to the continuous improvement of the University.

In 2017 UPE again submitted the SIGQ to the auditing process by the A3ES, and the CAE's visited us in September 2017, the CAE was constituted by 6 elements, one element belonging to a nonPortuguese European institution, and the remaining belong to institutions national authorities. The CAE was auditing the SIQG of Portucalense University for 3 consecutive days.

The quality management policy of the UPT establishes and formalizes the institutional commitment to quality, support to the objectives, functions and documentation of the system. It is defined and approved by the Directorate of El and Rectory, being communicated to the entire UPT community: teachers, non-teachers and students, disseminated through the UPT website. The design and structuring of the quality management and guarantee system (SGGQ) is ensured by the involvement of UPT's management and governance bodies, as well as the entire structure. In order to guarantee the alignment of all in the pursuit of the policy and improvement objectives. The SGGQ is structured according to the attached manual, and the Quality and Evaluation Office (GQA) is responsible for its dynamization, coordination and monitoring. The GQA, in addition to the Quality Manager, includes a Vice-Director as a representative of the academic / scientific area, and the human resources manager, as representative of the support areas. The quality assurance and management structure also 
includes the Quality Advisory Council (CCQ) and the $\mathrm{G} 12$ group. The functions of the different actors are summarized briefly: Direction: global supervision of activities, direct coordination of the activities of the area managers (who control and monitor the various services), the Conservation and Restoration Clinic, accompanies the PMD (Performance Monitoring Plan) and the SAD. Rectory: coordinates and monitors the activities of departmental directors and responsible for Organic Units; accompanies the Performance Monitoring Plan, SAD and RAD. The Pedagogical Council validates the pedagogical guidelines and the methods that ensure the proper development and control of the teaching and learning processes, promote the evaluation of the pedagogical performance of the teachers by the students themselves and the students.

The analysis and dissemination of the results, pronounces on the creation and alteration of new courses. Scientific Council, evaluates the plan of activities of the UPT, deliberates on the proposals of teaching service; Is in charge of the creation and alteration of study cycles and approves the respective plans and faculty, pronounces on the establishment of protocols with other national and international institutions, deliberates on the attribution of equivalences and questions of enrollment. Student Provider, is a Teacher designated specifically to ensure the liaison between students, at the individual or collective level, and the academic bodies, receiving, analyzing, referring and responding to complaints or requests from students. Head of Department: guides, supervises and coordinates all activities necessary for the proper functioning of the department, based on its Plan of Activities. Head of Department is responsible for the monitoring of teaching and learning, as well as the taking of actions during the school year, and should prepare the Activity Report, taking into account the Course Coordination, the School Board Minutes, the Student Meeting, Student Provider, Pedagogical Survey, RAD and PMD, Teacher Self-Assessment Surveys, Individual Teacher Report, Results of Internal Audits, Results of Complaints / Suggestions. School Council of the Department, pronounces on proposals Concerning the operation of the department. Course Committee: has as main objective to create a constructive dialogue between teachers and students, implement actions to monitor and improve study cycles. Course Coordinators, it is their responsibility to promote the quality of the course, through an effective organization, accompanying students, promoting the course, presiding over the respective Commission, being responsible for the elaboration of the Coordination Report, based on the minutes of the Course Committee, Pedagogical Inquiries and Student Performance. The $\mathrm{RU}$ Board directs, supervises and coordinates all research activities, assuring the pursuit of its objectives, based on the Activity Plan. It is responsible for monitoring the research activity, and should prepare the Activity Report, taking into account the Reports of the researchers responsible for the projects, RAD and LDC, Indicators Of repositories, Individual Teacher / Researcher Reports, Internal Audits and Complaints / Suggestions; the Scientific Council of the RU, issues an opinion on the plan and the annual activity report. RU Coordination Committee: prepares the plan and the activity report, approves the creation of well-researched lines such as participation in $R \& D$ projects.

On December 14,2017 , the Institution succeeded in certifying quality for the A3ES, for a maximum period of six years, and also succeeded on February 5, 2018, when certifying NP EN ISO 9001: 2015.

These certifications enabled Portucalense University to focus on continuous improvement through a variety of factors, such as the standardization and documentary control, the dematerialization of processes, the speed in solving problems, the implementation of a performance evaluation system with the aim of improving performance, the creation of a performance monitoring plan measuring all the quantitative and trend indicators, the creation of a risk-based analysis, where, in a preventive way, anticipates possible problems, among others.

The central objective in the investment of this type of certifications, objective reached by the Portucalense University, is, beyond a seal of confidence, the continuous improvement, being this one primordial for the growth and social affirmation of HEI. The commitment to these certifications, by the UPT, has made the teaching and non-teaching collaborators create the habit of knowing how to interact with the change, which is effectively the greatest difficulty in this type of systems.

\section{CONCLUSIONS}

The aim of this study was to avoid the easier path, common in scenarios of circumscribed cases, which reveal specific knowledge of specific scenarios that take small portions of reality, presenting isolated empirical data, not contextualized, without data exploration in terms of their relationships as context and meaning for higher education decision makers. 
This work was carried out with an ethnographic case study, that is, an in-depth study of an educational phenomenon with an emphasis on its singularity and taking into account the principles of ethnography, assuming itself as an in-depth study of a single case, Portucalense University, through participant observation and documentary analysis.

This work offers a non-reductionist view, assuming itself as a useful contribution to the understanding of a complex reality that is intended progressively less subjective: quality in higher education. It is considered that the evolutionary process of the HEl in question is a success story, because in addition to achieving its objective in the certifications, was effectively able to put into practice the continuous improvement of its various processes.

The paper provides an overview of learning community theory and core practices and an original case study of a portuguese institution that have made learning community a long-term focus of quality improvement efforts. This work stands out for its particularity, for its complete and literal description of the situation investigated, for the large number of variables and their interactions over time, and for the heuristic, leading us to rethink the investigated phenomenon. This paper presents potential contribution to the problems of educational practice in European higher education, providing valuable information for practical measures and for policy decisions.

\section{REFERENCES}

[1] A3ES (2012a). Manual de Avaliação, Agência de Avaliação e Acreditação do Ensino Superior, Lisboa. http://www.a3es.pt/pt/acreditacao-e-auditoria/manual-de-avaliacao

[2] A3ES (2012b). Manual da Qualidade, Agência de Avaliação e Acreditação do Ensino Superior, Lisboa. http://www.a3es.pt/sites/default/files/Manual\%20da\%20Qualidade.pdf

[3] Costa-Lobo, C. \& Ferreira, A. T. (2012). Educação para a Carreira: Contributos para a Tomada de Decisão nas Transições Profissionais. In: Alves, J. S. \& Neto, A. M. S. (org.), Decisão: Percursos e Contextos (pp. 201-206). Vila Nova de Gaia: Eu Edito.

[4] Costa-Lobo, C. (2011). Abordagem sócio-cognitiva do ajustamento à carreira no ensino superior: o papel das actividades em grupo, da auto-eficácia e dos interesses (Tese de Doutoramento). Escola de Psicologia, Universidade do Minho, Braga, Portugal.

[5] ENQA, ESU, EUA \& EURASHE (2015). Standards and Guidelines for Quality Assurance in the European Higher Education Area (ESG). Brussels, Belgium.

[6] EUA (2003). Graz Declaration 2003 - Forward from Berlin: the Role of the Universities, European University Association, Brussels, September 2003.

[7] FINHEEC (2008). Audits of Quality Assurance Systems of Finnish Higher Education Institutions - Audit Manual for 2008-2011, Finnish Higher Education Evaluation Council, Helsinki.

[8] Jesus-Silva, N., Medeiros, A. M., Caramelo-Gomes, J.; Costa- Lobo, C. (2016). Quality in higher education: analysis and discussion of evaluative standards internal consistency. Proceedings of ICERI 2016. ISBN: 978-84-617-5895-1.

[9] Santos (2011). Análise Comparativa dos Processos Europeus para a Avaliação e Certificação de Sistemas Internos de Garantia da Qualidade, A3ES Readings 1, Agência de Avaliação e Acreditação do Ensino Superior (A3ES), Lisboa. http://www.a3es.pt/sites/default/files/ESTUDO_SIGQ_PT.pdf

[10] Sá, E., Dias, D, \& Sá, M. J. (2017). Towards the university entrepreneurial mission: Portuguese academics' self-perspective of their role in knowledge transfer. Journal of Further and Higher Education, DOI: 10.1080/0309877X.2017.1311998

[11] Sousa, C., Magalhães, M., Castro Lopes, F., Fernandes, S., Costa-Lobo, C. (2017). EHIS Method(C: Entrepreneurship Human Interaction Skills. In Christophe Loué \& Sonia Ben Slimane (Eds), Proceedings of the 12th European Conference on Innovation and Entrepreneurship ECIE 2017 (pp.644-652). Paris (France). ISBN: 978-1-911218-55-5. 